\title{
Compounds targeting multiple prostanoid receptors
}

\author{
David F Woodward ${ }^{1,2 *}$ and Jenny W Wang ${ }^{2}$ \\ ${ }^{1}$ Department of Bioengineering, Imperial College London, South Kensington, London, UK \\ ${ }^{2}$ JeniVision Inc. Irvine, California, USA
}

\begin{abstract}
The prostanoids are a large family of oxygenated fatty acids that mediate numerous biological effects. They are biosynthesized from arachidonic acid by the enzymes cyclo-oxygenase- 1 and -2 and inhibitors of these enzymes are widely indicated as drugs for treating inflammation, pain, and fever. Following structural elucidation of the pharmacologically defined prostanoid receptors, drug design largely switched from COX inhibitors to pharmacology. Potent and selective antagonists for each of the prostanoid receptors $\left(\mathrm{DP}_{1-2}, \mathrm{EP}_{1-4}, \mathrm{FP}, \mathrm{IP}, \mathrm{TP}\right)$ were developed but these have not translated into widely used new drugs, despite the clear importance of prostanoids in disease. Responding to this situation, a new polypharmacological approach was adopted whereby multiple activities were embodied in a single molecule. The receptors selected for antagonism were selected based on known roles in mediating inflammation and fibrosis. Receptors opposing pro-inflammatory events, notably $\mathrm{EP}_{2}$, were left open so that $\mathrm{PGE}_{2}$ may be converted from a pro-inflammatory to an endogenously released anti-inflammatory mediator. This resulted in compounds with greater anti-inflammatory efficacy than antagonists selective for a single prostanoid receptor and cyclo-oxygenase inhibitors. Next steps in the evolution of this class of multi-targeting agents are opined on; a wider therapeutic spectrum, agonist/antagonist hybrids, and longer-acting multi-targeting prostanoid receptor antagonists.
\end{abstract}

The major prostanoids are prostaglandin $(\mathrm{PG}) \mathrm{D}_{2}, \mathrm{E}_{2}, \mathrm{~F}_{2 a}$, prostacyclin $\left(\mathrm{PGI}_{2}\right)$, and thromboxane $\mathrm{A}_{2}\left(\mathrm{TxA}_{2}\right)$. They are formed in a two stage biosynthetic pathway, initially involving the oxidation of arachidonic acid by cyclo-oxygenase (COX) enzymes 1 and/or 2 and then conversion to the final products by specific PG synthases. In addition to the major prostanoids, there are many other C-20 oxygenated fatty acids that are members of the prostanoid family. Despite being a large molecular family, the activities of all are dictated by nine major receptor subtypes encoded by separate genes. The receptor nomenclature is based on preferential interaction with the major prostanoids and, therefore, the individual receptor subtype designations are $\mathrm{DP}_{1}, \mathrm{DP}_{2}, \mathrm{EP}_{1}, \mathrm{EP}_{2}, \mathrm{EP}_{3}, \mathrm{EP}_{4}, \mathrm{FP}$, IP, and TP [1,2]. All are G-protein coupled receptors but $\mathrm{DP}_{2}$ is structurally quite different from the other prostanoid receptors [2]. The biosynthetic pathways for the major prostanoids and their receptors are summarized in Figure 1.

Receptor selectivity has long been fundamental in drug design programs. This has been the quintessential principal in prostanoid-based drug design, given the number of naturally occurring prostanoids, their pleotropic effects, and the impractically narrow margins of receptor selectivity inherent in the endogenous PG ligands. Glaucoma represents a significant success in the design of receptor selective prostaglandin mimetics, which became first-line therapy. Selective FP agonists [3], the prostamide $\mathrm{F}_{2 a}$ analog bimatoprost [4] were all successful anti-glaucoma agents and now $\mathrm{EP}_{2}$ agonists look very promising [5]. This successful application of receptor selectivity does not appear to have translated into commercially successful prostanoid receptor antagonists. There is a clear disconnect here, prostanoids are indeed a major player in many diseases. Global prevention of prostanoid biosynthesis by inhibition of the cyclo-oxygenase (COX) enzymes provides invaluable remediation for numerous medical conditions. The reconnection and the potential way forward was considered to be compounds that antagonize multiple prostanoid receptors.

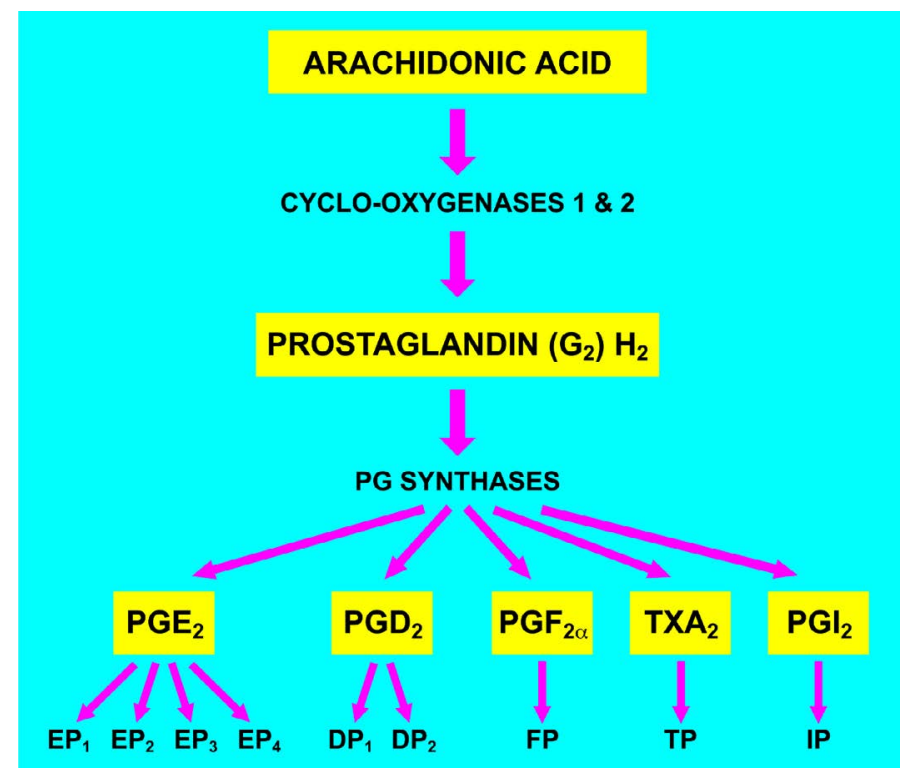

Figure 1. The biosynthesis of the major prostanoids and their receptors. Arachidonic acid is enzymatically oxidized by the cyclo-oxygenases 1 and 2 to the chemically unstable intermediates prostaglandin $\mathrm{G}_{2}$ and $\mathrm{H}_{2}\left(\mathrm{PGG}_{2}\right.$ and $\left.\mathrm{PGH}_{2}\right)$. $\mathrm{PGH}_{2}$ is then converted by specific prostaglandin (PG) synthases to the major prostanoids: $\mathrm{PGE}_{2}, \mathrm{PGD}_{2}, \mathrm{PGF}_{2}$, thromboxane $\mathrm{A}_{2}\left(\mathrm{TxA}_{2}\right)$, and prostacyclin $\left(\mathrm{PGI}_{2}\right)$. The major prostanoids preferentially interact with target receptors as follows: $\mathrm{PGE}_{2} \rightarrow \mathrm{EP}_{1}, \mathrm{EP}_{2}, \mathrm{EP}_{3}, \mathrm{EP}_{4}, \mathrm{PGD}_{2} \rightarrow \mathrm{DP}_{1}, \mathrm{DP}_{2}$; $\mathrm{PGF}_{2 \alpha},->\mathrm{FP} ; \mathrm{TxA}_{2}->$ TP; $\mathrm{PGI}_{2}->$ IP

${ }^{*}$ Correspondence to: David F Woodward, Department of Bioengineering, Imperial College London, South Kensington, London, UK, JeniVision Inc. Irvine, California, USA, E-mail: david.woodward@imperial.ac.uk

Key words: prostaglandins, receptors, antagonists, polypharmacology, multivalent Received: December 02, 2020; Accepted: December 23, 2020; Published: December 28, 2020 
The primary prostaglandins (PGs) preferentially interact with dedicated receptors as follows: $\mathrm{PGD}_{2} \rightarrow \mathrm{DP}_{1}, \mathrm{DP}_{2} ; \mathrm{PGE}_{2} \rightarrow \mathrm{EP}_{1}, \mathrm{EP}_{2}$, $\mathrm{EP}_{3}, \mathrm{EP}_{4} ; \mathrm{PGF}_{2 a} \rightarrow \mathrm{FP}$; prostacyclin $\left(\mathrm{PGI}_{2}\right) \rightarrow \mathrm{IP}$; thromboxane $\mathrm{A}_{2}$ $\left(\mathrm{TxA}_{2}\right) \mathrm{TP} \rightarrow[1,2]$. There is an entire repertoire of selective antagonists for each of the individual prostanoid receptors [2] but these do not seem to have lived up to expectations. This situation, considered and analyzed, led to the concept and design of PG antagonists that block multiple receptors, the prototypical compound being AGN 211377 [6]. This compound blocks those prostanoid receptors typically involved in mediating inflammation, fibrosis, and hyperalgesia ( $\mathrm{DP}_{1}, \mathrm{DP}_{2}, \mathrm{EP}_{1}, \mathrm{EP}_{4}$, $\mathrm{FP}$, and $\mathrm{TP})$ while leaving "anti-inflammatory" receptors $\left(\mathrm{EP}_{2}, \mathrm{IP}\right)$ open to stimulation by endogenously released prostanoids. AGN 211377 was more effective than cyclo-oxygenase inhibition or selective antagonism of any single prostanoid receptor in inhibiting cytokine/chemokine release from human macrophages [6]. These results translated to living animal models of inflammation. Therapeutic effects occurred not only in inflammatory leukocyte infiltration but also in retinal neovascularization and uveitis [7].

AGN 211377 had an appealing poly-pharmacological activity profile but it has a chemical backbone that closely resembles that of naturally occurring eicosanoids $[1,6]$, which resulted in unsatisfactory oral and ocular bioavailability [8]. This is a problem frequently addressed by medicinal chemistry and the solution lay in a dramatically different, non-eicosanoid chemical scaffold [8]. This class of compounds is represented by AGN 225660, which has a pyrazole based scaffold [8]. This compound retained all the anti-inflammatory properties of AGN 211377 and, in addition, was discovered to inhibit the release of IL-23 and IL-12p70 from human monocyte-derived dendritic cells [8].

AGN 211377 and AGN 225660 were both active in models of ocular inflammation and clearly exceeded the activity of cyclo-oxygenase inhibitors and antagonists selective for a single prostanoid receptor $[7,8]$. The prognosis would arguably be favorable for activity in other models of inflammation, such as rheumatoid and osteoarthritis. Many therapeutic properties of cyclo-oxygenase inhibitors are likely to be shared by multi-targeting prostanoid receptor antagonists, depending on those receptors present in the antagonist profile. Anti-pyretics is one potential use. A more interesting comparison would be as analgesics and in comparison with cyclo-oxygenase inhibitors. Pain management is an attractive area since every prostanoid receptor has been implicated in diverse pain models, except $\mathrm{DP}_{2}$ and TP $[1,2]$. Certain other diseases where there is an important inflammatory component, but not amenable to COX-inhibitor therapy, may also benefit from treatment with multi-targeting prostanoid receptor antagonists. Asthma provides one such example and this will be discussed later.

Although AGN 211377, AGN 225660 and their congeners block multiple pro-inflammatory prostanoid receptors, they partly exert their effects by transforming the bias of the endogenously released prostanoids from pro-inflammatory to anti-inflammatory mediators. This is achieved by leaving anti-inflammatory receptors, notably $\mathrm{EP}_{2}$ receptors, open to stimulation by locally released $\mathrm{PGE}_{2}$ [6]. This also means that a substantial portion of the anti-inflammatory activity of AGN 211377 and its congeners is reliant on the presence of adequate highly localized concentrations of $\mathrm{PGE}_{2}$. This creates uncertainty, highly localized concentrations of $\mathrm{PGE}_{2}$ are rarely known. If $\mathrm{EP}_{2}$ receptor agonist activity could be introduced into the pharmacological profile, more pronounced and consistent anti-inflammatory effects may be obtained. For the purpose of illustrating the comparative effects of AGN 211377 and an AGN 211377-like molecule with $\mathrm{EP}_{2}$ agonist properties, a morphological depiction is prophetically provided in
Figure 2. The highly activated state of an "angry" tissue macrophage (Figure 2a) is reduced by AGN 211377 (Figure 2b) and then almost returned to ground state when $\mathrm{EP}_{2}$ agonist activity is added to AGN 211377 pharmacodynamics (Figure 2c).

The possibility of designing hybrid $\mathrm{EP}_{2}$-agonist/ $\mathrm{DP}_{1}, \mathrm{EP}_{1}, \mathrm{EP}_{4}$, FP, TP antagonist multi-target molecules is presented in Figure 3. The structural similarity of the second generation pan PG receptor antagonist AGN 225660 and the $\mathrm{EP}_{2}$ agonist CP-533536 is shown in Figure 3. Such a molecule has not actually been invented to date but is conceivable.

An improved pharmacological profile "tailored" to the need of a particular tissue is an advantageous option for improved disease management. The prostanoid receptor expression profile in many human cells and tissues has been reported or can be obtained, from transcription mapping for example. Moreover, the functional activity of each expressed prostanoid receptor is available for many cells and tissues, including human. Asthma provides a suitable and highly relevant disease to illustrate how informed design of a poly-pharmacological drug targeting multiple prostanoid receptors may represent novel and highly effective therapy.

In asthma, the functional human prostanoid receptor pharmacology is known for nearly all cells and tissues involved in this disease. Cyclo-oxygenase drugs, which inhibit the global biosynthesis of prostanoids, do not meaningfully alter the disease. Nevertheless, by considering how a PG antagonist that blocks multiple receptors,
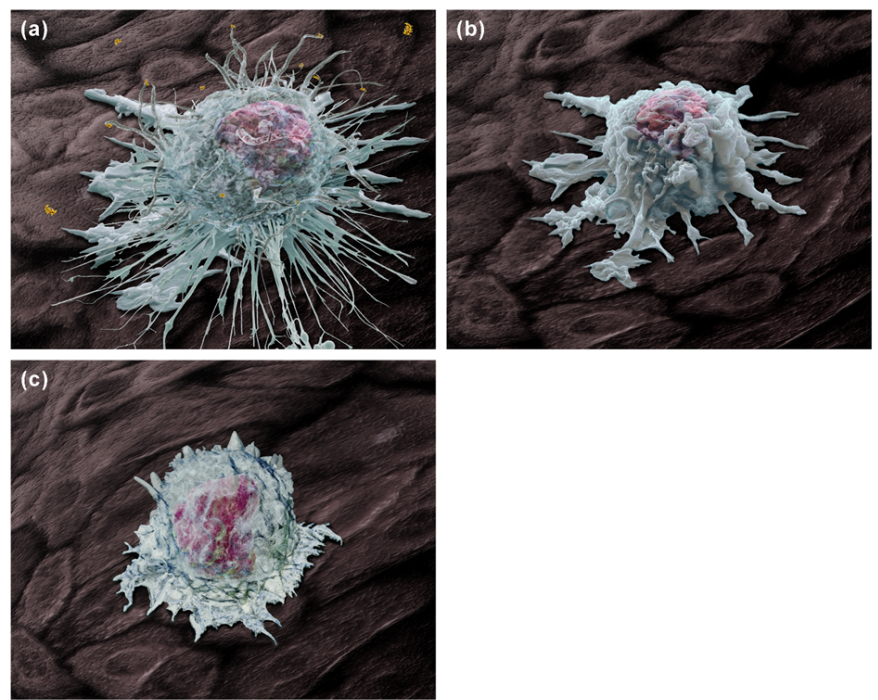

Figure 2. A prophetic morphological representations of tissue macrophage cells responding to inflammatory stimuli and following treatment with AGN 211377. Panel (a) depicts a highly activated tissue macrophage responding to the presence of pro-inflammatory stimuli; tissue debris and "foreign" matter, which can include free pathogens or pathogens bound with antibody molecules. Note the presence of numerous pseudopodial membrane extensions, which are rapidly formed as the cell becomes chemotactically polarized as it seeks out and entraps target particles. The cell surface is extremely ruffled as a result of increased cell membrane tension resulting from pseudopod extensions, formation of phagocytic cups into which target particles are enclosed, and endosomal compartments from which digested material and chemokine/cytokine compounds are released from the cell Panel (b) shows an activated macrophage in the presence of the anti-inflammatory agent AGN 211377, marked by a noticeable reduction in the extent and number of pseudopodia extensions. Chemokine/cytokine secretion would also be substantially reduced [6] but not eliminated. In panel (c), a macrophage that has largely resolved to a ground-state condition is shown following treatment with an AGN 211377-like molecular entity that also embodies $\mathrm{EP}_{2}$ receptor stimulant properties. The cell is quiescent and non-polarized, with markedly reduced cell membrane ruffling 
except $\mathrm{EP}_{2}$ and IP, may dramatically influence the course of the disease, the unique therapeutic approach provided by AGN 211377 may be envisioned (Figure 4).

Certain facets of bronchopulmonary disease cannot be reduced to isolation and study at the cellular or surgically excised tissue level, such as the cough reflex [9]. Nevertheless, those receptors involved in stimulating mast cells [10-12], eosinophils [13,14], airway constriction and airway smooth muscle hypertrophy $[15,16]$, cough $[17,18]$, and mucus hypersecretion [19] are known. The $\mathrm{EP}_{2}$ receptor is known to physiologically oppose the activation of mast cells, eosinpohils, and cytokine release from monocyte-derived macrophages and dendritic cells, all of which has been extensively documented [6,8,20-27]. The advantages of blocking multiple prostanoid receptors versus selective antagonism of a single prostanoid receptor can be envisioned by the diagram Figure 4 . The upper panel (a) of Figure 4 shows the airway

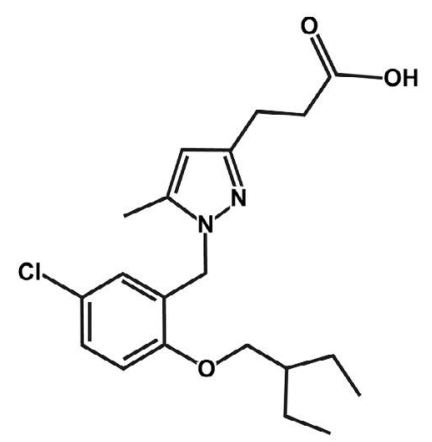

AGN 225660

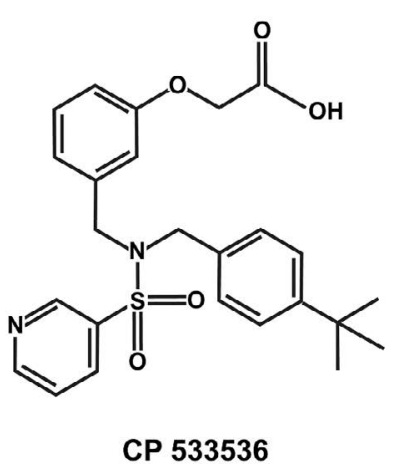

CP 533536
Figure 3. The structures of AGN 225660 and CP-533536 compared

(a) PROSTANOID RECEPTOR-MEDIATED EVENTS IN ASTHMA

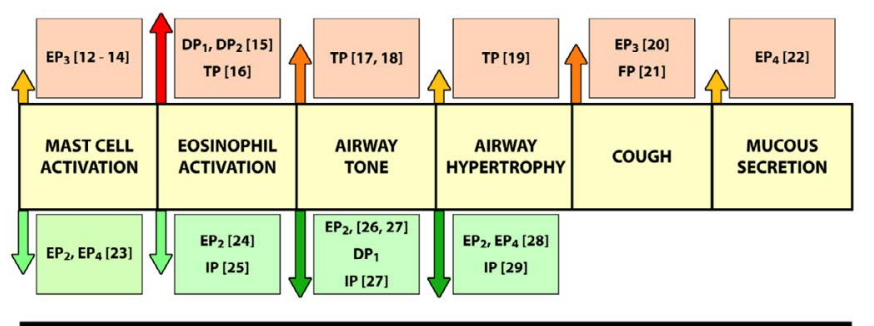

(b) PROSTANOID RECEPTOR-IMEDIATED EVENTS IN ASTHIMA AFTER TREATIMENT WITH AGN 211377

\begin{tabular}{|c|c|c|c|c|c|}
\hline $\begin{array}{l}\text { MAST CELL } \\
\text { ACTIVATION }\end{array}$ & $\begin{array}{l}\text { EOSINOPHIL } \\
\text { ACTIVATION }\end{array}$ & $\begin{array}{l}\text { AIRWAY } \\
\text { TONE }\end{array}$ & $\begin{array}{c}\text { AIRWAY } \\
\text { HYPERTROPHY }\end{array}$ & COUGH & $\begin{array}{c}\text { MUCOUS } \\
\text { SECRETION }\end{array}$ \\
\hline$E P_{2}[23]$ & $\begin{array}{l}E P_{2}[24] \\
\mathbb{P P}[25]\end{array}$ & $\begin{array}{c}E P_{2},[26,27] \\
\mathbb{I P}[27]\end{array}$ & $\begin{array}{l}\mathrm{EP}_{2}[28] \\
\mathrm{IP}[29]\end{array}$ & & \\
\hline
\end{tabular}

Figure 4. Panel (a) a diagrammatic overview of the role of the major prostanoids and their receptors in asthma. Activation of the pathological events characteristic of asthma are represented by upward vertical arrows $(\uparrow)$ above the midline depicted as a yellow block row. Reversal of the pathological events characteristic of asthma are represented by downward vertical arrows $(\downarrow)$ below the midline depicted as a yellow block row. Diametrically opposing effects are represented as follows; stimulation $\uparrow$, inhibition $\downarrow$. The role of airway prostanoid receptors is summarized as follows: mast cell activation $=\mathrm{EP} \uparrow$ $\mathrm{EP}_{2}, \mathrm{EP}_{4} \downarrow$; Eosinophil activation $=\mathrm{DP}_{1}, \mathrm{DP}_{2}, \mathrm{TP} \uparrow / \mathrm{EP}_{2}, \mathrm{IP} \downarrow$; airway tone $=\mathrm{TP} \uparrow / \mathrm{EP}_{2}, \mathrm{DP}_{1}$, $\mathrm{IP} \downarrow$ : airway hypertrophy $=\mathrm{TP} \uparrow / \mathrm{EP}_{2}, \mathrm{EP}_{4}, \mathrm{IP} \downarrow$; cough $=\mathrm{EP}_{3}, \mathrm{FP} \uparrow /$ ? $\downarrow$; mucous secretion $=\mathrm{EP} \uparrow /$ ? $\downarrow$. Panel (b) the pathophysiological events and symptoms of asthma following treatment with AGN 211377. Stimulant effects $(\uparrow)$ are virtually abolished by antagonism or opposed and reversed $(\downarrow)$ by $\mathrm{EP}_{2}$ and IP receptor mediated inhibitory effects constriction and various pro-inflammatory events that occur as a result of prostaglandin release into asthmatic human airways. $\mathrm{EP}_{3}$ receptors stimulate mast cells [10-12], $\mathrm{DP}_{1}, \mathrm{DP}_{2}$, and $\mathrm{TP}$ receptors activate eosinophils $[13,14]$, TP receptor activation causes bronchoconstriction and bronchial smooth muscle hypertrophy $[15,16], \mathrm{EP}_{3}$ and $\mathrm{FP}$ receptors are associated with the cough reflex $[17,18]$ and $\mathrm{EP}_{4}$ receptors stimulate mucus hypersecretion [19]. Following treatment with AGN 211377 and congeners, the $\mathrm{EP}_{2}$ receptor remains unoccupied and allows $\mathrm{PGE}_{2}$ to attenuate the inflammatory and deleterious airway smooth muscle effects typical of asthma. Similarly, immune modulation would be achieved by leaving open the $\mathrm{EP}_{2}$ receptors and blocking $\mathrm{EP}_{4}$ receptors [27]. The IP receptor would remain unoccupied, enabling released prostacyclin to relax the airways [24] reduce smooth muscle hypertrophy [26] and protect against inflammation [22,29]. A more expansive review of prostanoids in asthma and allergic diseases was provided in 2019 [29].

Corticosteroids are added to long-acting $\beta_{2}$-adrenoceptor agonists and long-acting muscarinic antagonists for the treatment of asthma and chronic obstructive pulmonary disease (COPD), since these diseases have a well-established and important inflammatory component. Given the more targeted anti-inflammatory effects of AGN 211377 and AGN 225660 , it is possible they are potentially a better and safer alternative to steroids in asthmatic children. These compounds will also relieve bronchoconstriction, just like long-acting $\beta_{2}$-adrenoceptor agonists and long-acting muscarinic antagonists. Clinical evaluation in asthma seems a worthwhile future proposition.

AGN 211377 and its congeners have a very attractive profile as potential anti-asthmatic drugs. Almost perfect but not quite. AGN blocks the $\mathrm{EP}_{4}$ receptor, which is inhibitory in mast cells [20] and antiproliferative [25]. This is arguably an inherent drawback but perhaps outweighed by the benefits of blocking the $\mathrm{EP}_{4}$ receptor. AGN 211377 and 225660 do not block $\mathrm{EP}_{3}$ receptors, which activate mast cells [1012] and stimulate coughing [17]. This could perhaps be remedied [30] by elaborating the core scaffolds of such pan PG antagonists to include $\mathrm{EP}_{3}$ receptor antagonism. As previously mentioned, the introduction of $\mathrm{EP}_{2}$ stimulant activity into the molecule may further enhance activity by improving upon the level of activity imparted by endogenous PGE It is noteworthy that allosteric potentiators have been designed that can increase the potency of $\mathrm{PGE}_{2}$ at the $\mathrm{EP}_{2}$ receptor by 4-5 fold [31]. In the case of asthma, the addition of IP agonist properties could be particularly useful, since endogenous prostacyclin is highly unstable and short-lasting. How far drug design of this class of agents needs to be go will ultimately be determined by clinical performance. Other diseases like asthma, where smooth muscle tone is a major factor, and that may benefit from this class of drugs include cardiovascular disease and prevention of pre-term labor.

It may be instructive to contemplate the design of prostanoid based therapeutics with economics as a consideration. Beyond cost of goods, longer acting drugs and poly-pharmacology, whereby two or more distinct biological activities are embodied in a single molecule, would be advantageous. There are lessons here from COPD and asthma therapeutics and from two of the oldest areas of pharmacology, adrenergics and cholinergics. The $\beta_{2}$-adrenoceptor has been a drug target for at least four decades, with improvements in duration of action to the point where such drugs are referred to as long-acting $\beta_{2}$ adrenoceptor agonists (LABAs) and even the term ultra-long-acting has been coined. Similarly, muscarinic receptor antagonists have found more regular use in treating asthma following the introduction of long-acting muscarinic antagonists (LAMAs). The advantages of these 
now commonly used medications are long-term control and reduced dosing frequency [32]. LAMAs and LABAs are increasingly used as combination therapy. A significant advance was the combination of both LABA and LAMA activities (MABAs) into a single molecule [33]. The MABAs, as exemplified by batefenterol [34] and AZD 8871 [35] are complex molecules with high molecular weights in the 750 range. By comparison with the MABAs, the prospect of creating small molecules with dual opposing activities (agonist and antagonist) at different receptor targets may be possible in the design of prostanoids. The close structural similarities of the major naturally occurring prostanoids is an advantage and has resulted in molecules that can selectively target 5-6 distinct prostanoid receptor subtype, albeit as antagonists $[6,8,30]$.

Since the MABAs produce long-lasting effects [32-36], the prospects for longer acting prostanoid antagonists may be realistic. At least one very advantageous requirement for protracted activity has been fulfilled for some prostanoid receptors, a knowledge of allosteric binding sites which previously assisted research on long-acting adrenergic agonists and cholinergic antagonists [36]. An allosteric binding site was proposed a decade ago for the $\mathrm{EP}_{2}$ receptor in the CNS [31]. Since then much has been learned about receptor-ligand binding by determining the crystal structure of prostanoid ligand-receptor protein complexes. To date the ligand bound crystal structure for $\mathrm{DP}_{2}$ (CRTh2) [37], $\mathrm{EP}_{3}$ $[38,39]$, and $\mathrm{EP}_{4}[40]$ receptors has been elucidated. In experiments determining the crystal structure of the $\mathrm{EP}_{4}$ receptor, the binding of a small molecule antagonist and an antibody were compared, with both entities binding allosterically to occlude the ligand binding pocket [40]. The extracellular loops thereby becoming an attractive proposition for prostanoid antagonist design. A series of allosteric FP antagonists were designed based on peptide mimicry [41]. Allosteric binding may also be used to introduce intracellular signal bias [42], conferring a further degree of specificity for a single receptor species. In prostanoid drug design this has been explored for both antagonist [43] and agonist [44] compounds. Returning to the design of AGN 211377-like antagonists for use in treating asthma, in a situation where the $\mathrm{EP}_{4}$ receptor produces both beneficial and unwanted activities, an antagonist which funnels receptor activation down a single signal transduction pathway may result in even better compound performance. Theoretically, effects on receptor-ligand resistance to internalization and inactivation may be introduced as a possible method of prolonging pharmacological activity. Finally, since monoclonal antibody therapy typically produces therapeutic agents with a two-week duration of action, their comparative binding properties [40] may be very instructive in designing longacting small molecules.

Multi-targeting a G-protein coupled receptor and an enzyme has also been accomplished. In order to achieve an improved effect on aqueous humor secretion, $\beta$-adrenoceptor antagonist/carbonic anhydrase inhibitor hybrids have been designed [45]. A drug design opportunity presented by the AGN 211377 chemical scaffold was the prevention of hydrolytic deactivation of the naturally occurring endocannabinoid anandamide by the enzyme Fatty Acid Amide Hydrolase (FAAH). Increasing endogenous anandamide levels by preventing its breakdown in the brain may produce analgesia $[46,47]$. For this reason, a series of compounds were designed from the initial prototypical pan PG antagonist chemical scaffold that also inhibited fatty acid amide hydrolase (FAAH) activity [48]. These compounds, exemplified by AGN 220653, were anti-inflammatory agents and with superior analgesic activity [48]. A hybrid pan PG antagonist/FAAH inhibitor may represent superior activity compared to COX-inhibitors or to FAAH inhibitors alone, the latter were disappointing as analgesics in an early clinical trial [49].
In summary, advanced prostanoid based therapies are reviewed herein. Compounds (AGN 211377 and 225660) were designed to simultaneously, selectively, and potently inhibit five receptors, all encoded by different genes. These compounds have, to date, proven to be more effective anti-inflammatory agents compared to cyclooxygenase inhibitors in animal models of ocular disease. Testing in animal models of arthritis, osteoporosis, asthma, pre-term labor, pain and cardiovascular disease will better elucidate their potential as a new class of drugs. The invention of small molecules simultaneously acting at multiple and diverse targets (AGN 220653) that mediate prostanoid and endocannabinoid functions has even been proven feasible.

\section{Acknowledgement}

The authors express their sincere appreciation to Clayton Spada Visual Communications, Beijing, China for the figures and illustrations.

\section{Conflicts of interest}

The authors declare no conflicts of interest.

\section{References}

1. Coleman RA, Smith WL, Narumiya S (1994) International union of pharmacology classification of prostanoid receptors: properties, distribution, and structure of the receptors and their subtypes. Pharmacol Rev 46: 205-229. [Crossref]

2. Woodward DF, Jones RL, Narumiya S (2011) International union of basic and clinical pharmacology: Classification of prostanoid receptors, updating 15 years of progress. Pharmacol Rev 63: 471-538. [Crossref]

3. Liljebris C, Selén G, Resul B, Stjernschantz J, Hacksell U (1995) Derivatives of 17-phenyl-18, 19, 20,-trinorprostagalndin $F_{2}$ alpha isopropyl ester: potential antiglaucoma agents J Med Chem 38: 289-304. [Crossref]

4. Woodward DF, Krauss AHP, Chen J, Liang Y, Li C, et al. (2003) Pharmacological characterization of a novel anti-glaucoma agent, Bimatoprost (AGN 192024). J Pharmacol Exp Ther 305: 772-785. [Crossref]

5. Woodward DF, Wang JW, Stamer WD, Lütjen-Drecoll E, Krauss AHP, et al. (2019) Anti-Glaucoma $\mathrm{EP}_{2}$ agonists, a long road that led somewhere. J Ocular Pharmacol 35: 469-474. [Crossref]

6. Wang JW, Woodward DF, Martos JL, Cornell CL, Carling RW, et al. (2016) Multitargeting of selected prostanoid receptors provides agents with enhanced antiinflammatory activity in macrophages. FASEB J 30: 394-404. [Crossref]

7. Woodward DF, Wang JW, Ni M, Bauer A, Martos JL, et al. (2017) In vivo studies validating multi-targeting of prostanoid receptors for achieving superior antiinflammatory effects. FASEB J 31: 368-375. [Crossref]

8. Woodward DF, Wang JW, Spada CS, Carling RW, Martos JL, et al. (2020) A second generation prostanoid receptor antagonist acting at multiple receptor subtypes. ACS Pharmacol \& Trans Sci 3: 1199-1210. [Crossref]

9. Maher SA, Belvisis MG (2010) Prostanoids and the cough reflex. Lung 188: 9-12. [Crossref]

10. Wang XS, Lau HY (2006) Prostaglandin E potentiates the immunology stimulated histamine release from human peripheral blood-derived mast cells through EP1/EP3 receptors. Allergy 61: 503-506. [Crossref]

11. Feng C, Beller EM, Bagga S, Boyce JA (2006) Human mast cells express multiple EP receptors for prostaglandin $\mathrm{E}_{2}$ that differentially modulate activation responses. Blood 107: 3243-3250. [Crossref]

12. Kondeti V, Al-Azzam N, Duah E, Thodeti CK, Boyce JA, et al. (2016) Leukotriene $\mathrm{D}_{4}$ and prostaglandin $\mathrm{E}_{2}$ signals synergize and potentiate vascular inflammation in a mast cell-dependent manner through cysteinyl leukotriene receptor 1 and $\mathrm{E}$ prostanoid receptor 3. J Allergy Clin Immunol 137: 289-298. [Crossref]

13. Suzuki Y, Asano K, Niimi K, Miyata J, Shiraishi Y, et al. (2004) TP-receptor mediated release of eosinophil chemotactic activity from human bronchial smooth muscle cells. Eur J Pharmacol 600: 133-139. [Crossref]

14. Senouvo FY, Tabet Y, Morin C, Albadine R, Sirois C, et al. (2011) Improved bioavailability of epoxyeicosatrienoic acids reduces TP-receptor agonist-induced tension in human bronchi. Am J Lung Cell Mol Physiol 301: 1675-1682. [Crossref] 
15. McKenniff MG, Norman P, Cuthbert NJ, Gardiner PJ (1991) BAY u3405, a potent and selective thromboxane $\mathrm{A}_{2}$ receptor antagonist on airway smooth muscle in vitro. $\mathrm{BrJ}$ Pharmacol 104: 585-590. [Crossref]

16. Suzuki Y, Asano K, Shiraishi Y, Oguma T, Shiomi T, et al. (2004) Human bronchial smooth muscle cell proliferation via thromboxane $\mathrm{A}_{2}$ receptor. PLEFA 71: 375-382. [Crossref]

17. Maher SA, Birrell MA, Belvisi MG (2009) Prostaglandin E2 mediates cough via the EP3 receptor: implications for future disease therapy. Am J Respir Crit Care Med 180: 923-928. [Crossref]

18. Stone R, Barnes PJ, Fuller RW (1985) Contrasting effects of prostaglandins E2 and F2 Alpha on sensitivity of the human cough reflex. J Appl Physiol 73: 649-653. [Crossref]

19. Akaba T, Komiya K, Suzaki I, Kozaki Y, Tamaoki J, et al. (2018) Activating prostaglandin E2 receptor subtype EP4 increases secreted mucin from airway goble cells. Pulm Pharmacol Ther 48: 117-123. [Crossref]

20. Kay LJ, Gilbert M, Pullen N, Skerratt S, Farrington J, et al. (2013) Characterization of the EP receptor subtype that mediates the inhibitory effects of prostaglandin E2 on IgE-dependent secretion from lung mast cells. Clin Exp Allergy 43: 741-751. [Crossref]

21. Sturm EH, Schratl P, Schuligoi R, Konya V, Sturm GJ, et al. (2008) Prostaglandin E inhibits eosinophil trafficking through E-prostanoid 2 receptors. J Immunol 181: 7273 7283. [Crossref]

22. Konya V, Sturm EM, Schratl P, Beubler E, Marsche G, et al. (2010) Endotheliumderived prostaglandin I (2) controls the migration of eosinophils. J Allergy Clin Immunol 125: 1105-1113. [Crossref]

23. Säfholm J, Manson ML, Bood J, Delin I, Orre AC, et al. (2015) Prostaglandin E inhibits mast cell-dependent bronchoconstriction in human small airways through the E prostanoid subtype 2 receptor. J Allergy Clin Immunol 136: 1232-1239. [Crossref]

24. Norel X, Walch L, Labat C, Gascard JP, Dulmet E, et al. (1999) Prostanoid receptors involved in the relaxation of human bronchial preparations. Br J Pharmacol 126: 867872. [Crossref]

25. Michael JV, Gavrila A, Nayak AP, Pera T, Liberato JR, et al. (2019) Cooperativity of E-prostanoid receptor subtypes in regulating signaling and growth inhibition in human airway smooth muscle. FASEB J 33: 4780-4789. [Crossref]

26. Belvisi MG, Saunders M, Yacoub M, Mitchell JA (1998) Expression of cyclooxygenase-2 in human airway smooth muscle is associated with profound reductions in cell growth. Br J Pharmacol 125: 1102-1108. [Crossref]

27. Poloso NJ, Urquhart P, Nicolaou A, Wang J, Woodward DF (2013) PGE2 differentially regulates monocyte-derived dendritic cells cytokine responses depending on receptor usage (EP2/EP4). Mol Immunol 54: 284-295. [Crossref]

28. Müller T, Dürk T, Blumenthal B, Herouy Y, Sorichter S, et al. (2010) Iloprost has potent anti-inflammatory properties on human monocyte-derived dendritic cells. Clin Exp Allergy 40: 1214-1221. [Crossref]

29. Peebles RS (2019) Prostaglandins in asthma and allergic diseases. Pharmacol Ther 193: 1-19. [Crossref]

30. Martos JL, Carling WR, Woodward DF, Wang JW, Kangasmetsa JJ (2016) Compounds act at multiple prostaglandin receptors giving a general anti-inflammatory response. US patent 9422273.

31. Jiang J, Ganesh T, Du Y, Thepchatri P, Rojas A, et al. (2010) Neuroprotection by selective allosteric potentiators of the EP2 receptor. Proc Nat Acad Sci 107: 2307-2312. [Crossref]

32. Wendell SG, Fan H, Zhang C (2020) G Protein-coupled receptors in asthma therapy: pharmacology and drug action. Pharmacol Rev 72: 1-49. [Crossref]
33. Hughes AD, Jones LH (2011) Dual-pharmacology muscarinic antagonist and $\beta_{2}$ agonist molecules for the treatment of chronic obstructive pulmonary disease. Future Med Chem 3: 1585-1605. [Crossref]

34. Hughes AD, Chen Y, Hegde SS, Jasper JR, Jaw-Tsai S, et al. (2015) Discovery of (R)1-(3-((2-chloro-4-((2-hydroxy-2-(8-hydroxy-2-oxo-1,2-dihydroquinolin-5-yl)ethyl) amino)methyl)-5-methoxyphenyl)amino)-3-oxopropyl)piperidin-4-yl[1,1'-biphenyl]2-ylcarbamate (TD-5959, GSK961081, batefenterol): First-in-class dual pharmacology multivalent muscarinic antagonist and $\beta_{2}$ agonist (MABA) for the treatment of chronic obstructive pulmonary disease (COPD). J Med Chem 58: 2609-2622. [Crossref]

35. Aparici M, Carcasona C, Ramos I, Montero JL, Otal R, et al. (2019) Pharmacologica profile of AZD8871 (LAS191351), a novel inhaled dual M3 receptor antagonist/ $\beta$ adrenoceptor agonist molecule with long-lasting effects and favorable safety profile. $J$ Pharmacol Exp Ther 370: 127-136. [Crossref]

36. Wold EA, Chen J, Cunningham KA, Zhou J (2019) Allosteric modulation of class A GPCRs: targets, agents, and emerging concepts. J Med Chem 62: 88-127. [Crossref]

37. Wang L, Yao D, Deepak RNVK, Liu H, Xiao Q, et al. (2018) Structures of the PGD receptor CRTH2 reveal novel mechanisms for ligand recognition. Mol Cell 72: 48-59. [Crossref]

38. Morimoto K, Suno R, Hotta Y, Yamashita K, Hirata K, et al. (2019) Crystal structure of the endogenous agonist-bound prostanoid receptor $\mathrm{EP}_{3}$. Nat Chem Biol 15: 8-10. [Crossref]

39. Audet M, White KL, Breton B, Zarzycka B, Han GW, et al. (2019) Crystal structure of misoprostol bound to the labor inducer prostaglandin $\mathrm{E}_{2}$ receptor. Nat Chem Biol 15: 11-17. [Crossref]

40. Toyoda Y, Morimoto K, Suno R, Horita S, Yamashita K, et al. (2019) Ligand binding to human prostaglandin $\mathrm{E}$ receptor $\mathrm{EP}_{4}$ at the lipid-bilayer interface. Nat Chem Biol 15: 18-26. [Crossref]

41. Mir FM, Atmuri NDP, Bourguet CB, Fores JR, Hou X, et al. (2019) Paired utility of azo-amino acyl proline and indolizidinone amino acid residues for peptide mimicry: conception of prostaglandin $\mathrm{F} 2 \alpha$ receptor allosteric modulators that delay preterm birth $J$ Med Chem 62: 4500-4525. [Crossref]

42. Kenakin TP (2012) Biased signaling and allosteric machines: new vistas and challenges for drug discovery. Br J Pharmacol 165: 1659-1669. [Crossref]

43. Goupil E, Tassy D, Bourguet C, Quiniou C, Wisehart V, et al. (2010) A novel biased allosteric compound inhibitor of parturition selectively impedes the prostaglandin F2 $\alpha$ mediated Rho/ROCK signaling pathway. J Biol Chem 285: 25624-25636. [Crossref]

44. Ogawa S, Watanabe T, Sugimoto I, Moriyuki K, Goto Y, et al. (2016) Discovery of $\mathrm{G}$ protein-biased EP2 receptor agonists. ACS Med Chem Lett 7: 306-311. [Crossref]

45. Nocentini A, Ceruso M, Bua S, Lomelino CL, Andring JT, et al. (2018) Discovery of $\beta$-adrenergic receptors blocker-carbonic anhydrase inhibitor hybrids for multitargeted antiglaucoma therapy. J Med Chem 61: 5380-5394. [Crossref]

46. McKinney MG, Cravatt BF (2005) Structure and function of fatty acid amide hydrolase. Ann Rev Biochem 74: 411-432. [Crossref]

47. Maione S, Costa B, Di Marzo V (2013) Endocannabinoids: a unique opportunity to develop multitarget analgesics. Pain 154: S87-S93. [Crossref]

48. Ligresti A, Silvestri C, Vitale RM, Martos JL, Piscitelli F, et al. (2019) FAAH-catalyzed C-C bond cleavage of a new multi-target analgesic drug. ACS Chem Neurosci 10: 424 437. [Crossref]

49. Huggins JP, Smart TS, Langman S, Taylor L, Young T, et al. (2012) An efficient randomized, placebo-controlled clinical trial with the irreversible fatty acid amide hydrolase-1 inhibitor PF-04457845, which modulates endocannabinoids but fails to induce effective analgesia in patients with pain due to osteoarthritis of the knee. Pain 153: 1837-1846. [Crossref]

Copyright: C2020 Woodward DF. This is an open-access article distributed under the terms of the Creative Commons Attribution License, which permits unrestricted use, distribution, and reproduction in any medium, provided the original author and source are credited. 